\title{
Inflation, Central Bank Independence and the Legal System
}

\author{
Bernd Hayo ${ }^{*}$ \\ and \\ Stefan Voigt $^{* *}$
}

\begin{abstract}
:
We argue that a higher degree of de facto independence of the legal system from the other government branches as well as public trust in the legal system may reduce the average inflation record of countries through a direct and an indirect channel. The direct channel works by affecting potential output, while the indirect channel helps to increase the de facto independence of the central bank. In the empirical section of the paper, we present evidence in favor of both channels in a sample containing both industrial and Third World countries. A model that contains legal trust in addition to de jure central bank independence, checks and balances within government, and openness can explain $60 \%$ of the variation in the logarithm of the inflation rate.
\end{abstract}

Key Terms: Judicial Independence, Legal Trust, Central Bank Independence, Inflation.

JEL classification: D 72, D 78, H 11, K 42

* Philipps-University Marburg, Department of Economics (FB02), Universitaetsstr. 24, D35032 Marburg, Germany, Phone: +49-6421-2823091, Fax: +49--6421-2823088, Email: hayo@wiwi.uni-marburg.de.

** University of Kassel and ICER, Torino; Department of Economics, University of Kassel, Nora-Platiel-Str. 4, D-34107 Kassel, Germany, Phone: +49-561-804-3089, Fax: +49-561804-2818, Email: voigt@wirtschaft.uni-kassel.de.

The authors wish to thank Tobias Göthel for excellent research assistance, Jochen Michaelis for helpful comments, and Jakob de Haan, Jan-Egbert Sturm, Phil Keefer and David Stasavage for sharing their data with us. 


\section{Introduction}

The determinants of inflation have received broad attention over the last decade: formal central bank independence was shown to be a good predictor for low inflation in OECD countries, whereas the turnover rate of central bank governors has been identified as an important determinant of inflation rates in Less Developed Countries (some of the original contributions are Cukierman 1992, Cukierman et al. 1992, Debelle and Fisher 1995, Grilli et al. 1991, and Posen 1993. Recent surveys of the field are Berger et al. 2001 and Hayo and Hefeker 2002).

The creation of a (formally) independent central bank by a government is usually interpreted as an attempt to reduce its problem of credibly committing to a policy of stable money. It has been shown (Kydland and Prescott 1977) that governments with authority over money supply are subject to time-inconsistent preferences: the promise of expanding monetary supply according to some fixed rule is not credible because once long-term contracts have been agreed upon byprivate actors, the government has an incentive to expand money supply by more than promised. The delegation of monetary authority to independent central banks with conservative governors (Rogoff 1985) is often considered to be one way of escaping the commitment problem.

Yet, the empirical finding that a close correlation between formally independent central banks and inflation rates only exists in OECD countries points to a possible shortcoming of this simplistic view: if government has the capacity to create a formally independent central bank, it might also be strong enough to overrule its decisions, simply ignore them, or abolish the independent central bank again. This has been coined second-order commitment problem (Moser 1999). One question immediately arises: what are the conditions that enable central banks to act independently of government interventions in some countries but not in others? One answer has recently been proposed by Keefer and Stasavage (2003) who argue that the number of veto players is crucial: the more veto players there are, the more likely is legal central bank 
independence (CBI) to correspond with factual CBI. In their paper, they did not put explicit emphasis on the potential role of the judiciary. In this paper, we argue that the factual independence of the judiciary is a potentially important variable for determining inflation through (i) a direct transmission channel (affecting natural unemployment and/or potential output) and (ii) an indirect transmission channel (affecting de facto $\mathrm{CBI}$ ). We measure the impact of the legal system by an indicator for de facto JI suggested by Feld and Voigt (2003) and, alternatively, by an indicator for legal trust, which has been derived from the World Values Survey (World Values Survey Study Group 2000).

We find that a high degree of de facto JI or legal trust is systematically correlated with the turnover rate of central bank governors, which can be interpreted as a crude proxy for (the inverse of) de facto CBI. Thus, the judiciary affects inflation indirectly via de facto CBI. In addition, we show that specifically legal trust helps to directly explain low inflation rates. If it is added to the equation conventionally used for estimating inflation, the coefficient of determination increases from 0.50 to 0.60 in our sample. Based on these results we argue that in order for monetary policy to be successful, it is not sufficient to set up a (formally) independent central bank but that other policy areas - such as the judicial one - explicitly need to be taken into account.

The paper is organized as follows: the next section contains a description of the theoretic rationale for the two major hypotheses, namely (i) that the degree of factual CBI might be influenced by factual judicial independence and that (ii) the inflation rate might be influenced by the factual independence of the judiciary independently from the degree of formal CBI. Section three introduces the econometric model, section four contains a discussion of the estimated results, and section five concludes. 


\section{On the Relevance of the Judiciary for Inflation}

Independence of both judiciary and central bank means that its representatives can expect their decisions to be implemented even if they are not in line with the (short-term) interests of government members. Independence also means that judges or board members of central banks do not have to anticipate other negative consequences as a result of their decisions such as (i) being expelled, (ii) being paid less, or (iii) being made less influential. We further propose to distinguish between de jure and de facto independence with regard to both CBI and judicial independence (JI). De jure CBI would be equivalent to CBI as measured on the basis of legal documents whereas de facto $\mathrm{CBI}$ would be equivalent to $\mathrm{CBI}$ as factually implemented. Early on, Cukierman $(1992,370)$ clarified that CBI does not mean that the board members can do anything but rather the ability to stick to the objective of price stability. Tighter constraints on the central bankers (e.g. on borrowing to the government) can thus translate into higher degrees of independence.

The second order commitment problem shortly described in the introduction implies that simply delegating competence to some formally independent agency such as a central bank might not be sufficient to turn promises into credible commitments. The capacity to credibly commit might depend on other institutional features such as a factually independent judiciary. If the judiciary is factually independent, the government is able to make credible commitments. The promise - made in $\mathrm{t}_{0}$ - to pay bondholders $\mathrm{x} \%$ interest on their bonds in $\mathrm{t}_{1}$ is credible if a third party, i.e. neither the government nor the bondholders, has the power to ascertain who has breached the contract and if its decisions are binding even if they are not in the interest of one of the parties, e.g. the government. This is exactly the definition of judicial independence chosen above. If the judiciary is factually independent in this sense, the government is restricted in its actions. But the flipside is that this enables the government to make credible commitments. In the example, interest rates can be expected to be lower. 
Due to the second order commitment problem, the delegation of competence to a formally independent central bank or judiciary is not sufficient to allow the government to make credible commitments. It is not de jure independence that counts but rather de facto independence. This theoretical point has recently been confirmed by empirical evidence. On the basis of 73 countries, Feld and Voigt $(2003,2004)$ show that de jure JI is largely irrelevant for economic growth, whereas de facto JI does seem to be conducive to economic growth in a significant and robust manner. With regard to $\mathrm{CBI}$, we expect similar results. In fact, the observation that de jure $\mathrm{CBI}$ is a good predictor for inflation rates only in OECD countries, whereas the turnover rate fares better in LDCs can be interpreted as corroboration of this insight. It would imply that in OECD countries, de jure $\mathrm{CBI}$ is approximately equivalent to de facto $\mathrm{CBI}$, whereas the two systematically deviate in LDCs. The main focus of our analysis will therefore be on de facto indicators. We distinguish between two transmission mechanisms through which a factually independent judiciary could be conducive to low inflation: a direct one and an indirect one. The indirect one is based on the assumption that a high degree of de facto JI leads to a high degree of de facto $\mathrm{CBI}$ (assuming a high level of de jure $\mathrm{CBI}$ ), which, in turn, leads to low levels of inflation. The direct one is based on the insight that high levels of de facto JI lead to more output. The indirect transmission channel is presented first.

The likelihood that factual CBI will remain low although CBI is formally high is (an inverse) function of the government's capacity to credibly commit to its promises. The relevant promise refers to a monetary policy which is carried out independently from the (short-term) interests of the government by a central bank. The government's capacity to credibly commit to its promises crucially depends on the factual independence that the judiciary enjoys. Ex post, the judiciary can be interpreted as an attempt of coming to terms with the commitment problem of the state. The laws passed by the legislature will be more credible if it is another branch that decides on their interpretation and enforcement. The hypothesis that a high degree of de facto JI is 
conducive to a high degree of de facto $\mathrm{CBI}$ is based on the assumption that a high degree of de facto JI can also be interpreted as a proxy for a high probability that government will remain within the constraints spelled out in legal documents, the constitution included. Only if the judiciary is factually independent from government interference can economic agents trust that formally passed laws will factually be implemented. A general expectation that formally passed laws will factually be implemented includes, of course, the expectation that a formally independent CBI will also turn out to be factually independent. The argument does not necessarily imply that the governing board of a central bank has the competence to take a government to court if it believes the government to renege on the rules concerning the bank's independence.

The courts should not be interpreted as a veto player who could detain the central bank from implementing its policies. But the courts might be able to act as a veto player against government in case it tries to detain the board members of the central bank from implementing a particular monetary policy. Thus they would not veto the central bank but rather the other branches of government that try to renege on the independence of the central bank. Keefer and Stasavage (2003) put forward an alternative institutional channel that leads to higher de facto CBI. They argue that the introduction of a formally independent central bank will be more credible if it takes place in a system with a high number of veto players. The presence of multiple veto players with different preferences makes government policies more difficult to change and thus more credible. Hence, a high number of veto players would make the degree of de jure $\mathrm{CBI}$ a reliable proxy for de facto $\mathrm{CBI}$.

Let us now turn to the non-CBI related transmission mechanism, i.e. to the hypothesis that a high degree of de facto JI does not work via a high degree of de facto CBI, but rather influences the inflation rate directly. This argument can be demonstrated within the framework of two simple but widely-used models. Our first direct argument linking inflation and de facto JI starts 
from the assumption that an independent and trustworthy legal system reduces transaction costs in the economy, as contracts can be more easily enforced and risk premia will be lower. Trust can be interpreted as another way to solve the time-consistency problem mentioned above. If general legal trust is high, private agents will not expect a government to renege on its promises by, for example, initiating a burst of unanticipated inflation for achieving short-term economic objectives. If the probability of surprise inflation is low, wage contracts need not contain a premium, leading to higher degrees of price stability. In addition, the danger that supply shocks cause sustained second-round effects through a wage-price spiral can be avoided. Again, private agents do not expect the government to additionally boost prices through lose monetary policy. This line of reasoning can be illustrated using the seminal model by Barro and Gordon (1983), which has been primarily used to illustrate the consequences of time-inconsistency within the framework of monetary policy setting, the indirect channel from the legal system via CBI to inflation sketched above. In its simplest form the model consists of the following two equations:

Phillips-curve: $\quad \mathrm{u}=\mathrm{u}^{\mathrm{n}}-\alpha\left(\pi-\pi^{\mathrm{e}}\right)$,

CB loss function: $\quad \mathrm{L}(\mathrm{u}, \pi)=\mathrm{u}+\gamma \pi^{2}$, where: $\pi=$ inflation rate,

$$
\begin{aligned}
& \pi^{\mathrm{e}}=\text { rationally expected inflation rate, } \\
& \mathrm{u}=\text { unemployment rate, } \\
& \mathrm{u}^{\mathrm{n}}=\text { natural unemployment rate, } \\
& \gamma=\text { relative weight of inflation in central bank loss function, } \\
& \alpha=\text { inflation-unemployment trade-off parameter. }
\end{aligned}
$$

The conventional argument related to CBI focuses upon the size of the expected inflation rate in conjunction with $\gamma$. It is argued that a higher degree of credible inflation aversion reduces the time-inconsistency problem induced by the incentive of the central bank to surprise the private agents. This can be achieved by placing a high and credible weight upon the inflation objective, 
i.e. $\gamma$ should be high. It is here where, for instance, Keefer and Stasavage (2003) bring in their hypothesis of a high number of veto players. Here we would like to stress a different relationship. First, we assume that a more independent judiciary or trusted legal system reduces transaction costs. Second, lower transaction costs cause overall economic efficiency to improve, which again will cause a fall in the natural unemployment rate. This direct effect of the legal system on the inflation rate is due to the specification of the Phillips-curve, which implies that following a reduction in the natural rate of unemployment inflation will also be lower in the rational expectations long-run equilibrium.

A second framework that helps to illustrate the direct channel from the legal system to inflation is the Svensson model (1997), which describes an economy using three equations.

Aggregate supply curve: $\quad \pi_{\mathrm{t}+1}=\pi_{\mathrm{t}}+\alpha_{1} \mathrm{y}_{\mathrm{t}}+\varepsilon_{\mathrm{t}+1}$,

Aggregate demand curve: $y_{t+1}=\beta_{1} y_{t}-\beta_{2}\left(i_{t}-\pi_{t+1 \mid t}\right)+\eta_{t+1}$,

Central bank loss function: $L=\mathrm{E}_{\mathrm{t}} \sum_{\tau=\mathrm{t}}^{\infty} \delta^{\tau-\mathrm{t}} \frac{1}{2}\left[\left(\pi_{\mathrm{t}}-\pi^{*}\right)^{2}+\lambda \mathrm{y}_{\mathrm{t}}^{2}\right]$,

where: $\pi_{\mathrm{t}}=$ inflation in period $\mathrm{t}$,

$\mathrm{y}_{\mathrm{t}}=$ output gap $\left(\mathrm{y}_{\mathrm{t}}-\mathrm{y}^{*}\right)$ in period $\mathrm{t}$,

$\mathrm{y}^{*}=$ potential output,

$\pi_{t+1 \mid t}=$ expectation of $\pi_{t+1}$ in period $t$,

$\pi^{*}=$ central bank's inflation target,

$\lambda=$ relative weight on output stabilization.

Aggregate supply is characterized by a Phillips-curve, which describes the change of inflation as dependent upon the lagged output gap. Lagged income and real interest rates determine 
aggregate demand. The central bank minimizes its loss function by optimally adjusting its monetary policy instrument, the short-term nominal interest rate.

Now the argument linking inflation and de facto JI starts from a related but slightly different angle, namely the relationship between real growth and potential output. As demonstrated by Feld and Voigt (2003), higher de facto JI facilitates real growth. Since this is not a business cycle phenomenon but a long-term trend, it will affect potential output positively. The output gap in the aggregate supply curve becomes negative. In the next period, this effect will start generating downward pressure on the inflation rate. Since the inflation rate is persistent, there will be a gradual dynamic adjustment towards a lower inflation rate. At the same time, the central bank will begin to reduce interest rates to exploit the gain in terms of lower inflation for more output. The resulting increase in actual output will start narrowing the output gap until it is zero in equilibrium. While the equilibrium inflation rate will be the same before and after the positive shock in potential output, the average inflation rate computed over the relevant adjustment period will be lower in the situation after the shock. Note that this channel works for different combinations of central bank preferences and economic structures. Both economic structure and preferences will influence the dynamic path of prices and thereby the average inflation rate over the transitional period. For instance, a high value for $\lambda$ leads to a gradual adjustment of inflation to its long-run target, as the central bank tries to avoid large negative output fluctuations. Since we do not know the structural and preference parameters in practice, it is difficult to make precise quantitative predictions. However, at least qualitatively, higher de facto JI will lead to lower average inflation rates independently of any time-inconsistency considerations.

To summarize, we have developed two theoretical hypotheses that link inflation and legal system both in a situation of a long-run equilibrium as well as a business cycle adjustment situation. We call this a direct effect of the legal system on inflation, as it does not involve the 
intermediary stage of CBI, which lies at the heart of the previous hypotheses discussed in the literature. Hence, we would expect that a higher degree of judicial independence or confidence in the legal system should lead to lower inflation over and above their effect on the credibility of monetary policy through CBI.

\section{Estimation Approach and Data Description}

So far, two main hypotheses have been developed: firstly that de facto JI should be a good predictor for de facto $\mathrm{CBI}$ and secondly that indicators signaling a high degree of factual JI or a high degree of confidence of the population in the legal system should affect the inflation rate directly. In order to test the first hypothesis, some proxy for factual CBI is needed. Most previous studies have relied on the turnover rate of central bank governors (defined as "the actual average term of office of CB governors") which has been suggested by Cukierman (1992, 383) or a modified concept, namely the political vulnerability of central bank governors which indicates the probability that central bank governors will be removed from their offices during the six months following a change in government (introduced by Cukierman and Webb 1995).

De facto CBI has thus been operationalized by the turnover rate (TOR) of central bank governors. The higher the turnover rate, the more dependent is the central bank governor perceived to be. This is, of course, a very crude proxy for the factual independence of a central bank. The government might have other means to influence monetary policy than simply getting rid off the central bank governor. In fact, the expulsion of a central bank governor can even be interpreted as the governor having resisted government influence because otherwise the government might not have resorted to such a drastic means as firing the governor. Indeed, it could even be argued that central bank governors who always act according to the wishes of government have a very low probability of ever being fired. Interpreted like this, low turnover 
rates could even stand for low independence! However, due to the lack of better proxies, we rely on the TOR here too as a proxy for de facto CBI (Cukierman and Webb 1995).

The employed indicator for de facto JI is analyzed in more detail in Hayo and Voigt (2003). For simplicity, this indicator measures the independence of the highest court of a country, no matter whether it is a supreme court or a constitutional court. In many states, the judiciary is made up of thousands of decision-makers and, therefore, radical simplification is necessary. The focus on the highest court seems warranted because even though judges are personally independent, the ultimate control of court decisions lies with the highest courts, as they review - on the initiative of the parties involved - the lower court decisions. The independence of the highest court thus seems crucial.

Secondly, this indicator is constructed as an objective - as opposed to subjective - indicator. A subjective indicator of de facto JI would ask for the perception of independence amongst those being polled. For those who live under the respective rules, their perception is surely an important element determining their behavior. However, the norms of what an ideally independent judiciary would look like will most likely be different in different parts of the world. Data obtained by polls are thus not easily comparable and the new de facto JI indicator is therefore based on factual information. In principle, anybody measuring de facto JI in the countries covered should end up with exactly the same data (see the Appendix for a more detailed description of the de facto JI indicator). The resulting indicator for de facto JI lies between 0 and 1 and is available for 73 countries.

We propose to test the indirect channel between inflation and de facto JI by estimating the following regression:

(1) $\mathrm{TOR}=\beta_{0}+\beta_{1}$ de facto $\mathrm{JI}+\beta_{2} \mathrm{CEO}+\varepsilon$ 
CEO is a control variable that captures the formal term of office. A higher turnover rate due to a shorter formal length of office should not be interpreted as a sign of low credibility which is why we control for it. Our theory predicts a negative sign for de facto JI.

As argued above, de facto CBI might be determined by the degree of checks and balances as well as by the degree of de facto JI. Keefer and Stasavage (2003) propose a model that shows the importance of veto powers, measured by the logarithm of institutional checks, on the turnover rate. It includes the formal term of office of the CEO and the interaction term of their checks variable with the term length of the CEO. Adding de facto JI as an additional regressor, we estimate:

(2) $\mathrm{TOR}=\beta_{0}+\beta_{1} \mathrm{CEO}+\beta_{2}$ de facto $\mathrm{JI}+\beta_{3}$ LnChecks $+\beta_{4}($ LnChecks $*$ CEO $)+\varepsilon$

Regarding the test of the direct channel of de facto JI on inflation, we estimate the following equation:

(3) LnInflation $=\beta_{0}+\beta_{1}$ de facto $\mathrm{JI}+\beta_{2}$ de jure $\mathrm{CBI}+\beta_{3} \mathrm{OPEN}+\varepsilon$

Here we add two control variables; the indicator of de jure CBI, which goes back to Cukierman et al. (1992) and the degree of openness (OPEN). ${ }^{1}$ Romer (1993) argues that policy makers have fewer incentives to inflate ex post as imports increase as a share of total consumption. ${ }^{2}$

A larger share of the variation in inflation rates may be explained if the veto hypothesis based on checks and balances put forward by Keefer and Stasavage (2003) is interpreted as complementary to our approach. The authors use two different indicators for checks and balances: the political constraints indicator (POLCON) developed by Henisz (2000)which takes

${ }^{1}$ Forder (1996) and (1998) provides some powerful conceptual and data-based comments on de jure CBI measures.

2 Openness is defined as imports of goods and services divided by GDP. The data are from the IMF International Financial Statistics. 
into consideration the number of formal constitutional veto points present in a political system, the issue whether the veto points are controlled by representatives of different parties, and the cohesiveness of the majority that controls each veto point. A high value indicates the existence of many independent branches of government with veto power over policy change. The second measure for checks and balances (CHECKS) was developed by Keefer (2002) and does not only recognize the number of veto players but also takes the electoral rules into account as they affect the cohesiveness of governing coalitions.

Since we specifically focus upon the role of the legal system, it seems interesting to combine the empirical approaches based on veto powers within the executive and the legislative and to test for an additional and direct influence of the judicial system on the inflation rate.

(4) Ln Inflation $=\beta_{0}+\beta_{1}$ de facto $\mathrm{JI}+\beta_{2}$ de jure $\mathrm{CBI}+\beta_{3} \mathrm{OPEN}+\beta_{4} \mathrm{POLCON}+$

$$
\beta_{5}(\mathrm{POLCON} * \mathrm{CBI})+\varepsilon
$$

Finally, we test for the influence of the direct and the indirect channel of the legal system on inflation by adding the turnover rate to the previous model (see model 5).

$$
\begin{aligned}
& \text { Ln Inflation }=\beta_{0}+\beta_{1} \text { de facto JI }+\beta_{2} \text { de jure } \mathrm{CBI}+\beta_{3} \text { OPEN }+\beta_{4} \text { POLCON }+ \\
& \beta_{5}(\mathrm{POLCON} * \mathrm{CBI})+\beta_{6} \mathrm{TOR}+\varepsilon
\end{aligned}
$$

Note, however, that the turnover rate itself may depend on the inflation rate, i.e. central bank governors might have been removed from office because of an unsatisfactory result of monetary policy. If, on the one hand, we only found the indirect channel to be significant, it would be clear that an identified direct effect in models 3 and 4 is spurious. If, on the other hand, both effects turned out to be significant then this is evidence that both channels might be simultaneously present. 
In the theoretical section, it was argued that the general confidence of the population in the legal system might be an alternative to de facto JI. These two variables are positively correlated with a coefficient of 0.18 . We thus re-estimate equations 1-5 substituting de facto JI for legal trust. This variable is based on three waves of the World Values Survey (1981, 1990, and 1995-97). About 1000 randomly selected people in about 50 different countries and regions were asked a multitude of questions concerning values and attitudes (see World Values Study Group 2000). The actual question used here is worded as follows: "Please look at this card and tell me, for each item listed (here: The legal system), how much confidence you have in them, is it a great deal, quite a lot, not very much or none at all?"

\section{Estimation Results}

In the empirical analysis, the sample size varies depending on the included variables. At a minimum we have 34 countries, more than one third of which are not members of the OECD. The maximum sample size is 51 , with some half of the countries being OECD members. We commence the empirical analysis by investigating the existence of the indirect effect of the legal system via strengthening de facto CBI. The first model analyses the effect of de facto JI and legal trust on the central bank governor turnover rate, with the formal length of office as a control variable. To remove excessive non-normality from the data as a pre-condition for applying standard tests of significance, we introduce two dummy variables in Model 1a (Brazil and Uganda). However, the estimation results are not fundamentally different compared to a regression without these dummies. The diagnostic tests for Model 1 reveal no evidence of nonnormality, heteroscedasticity, or misspecification. We find that de facto JI has a significantly negative influence on the turnover rate. The formal length of office, on the other hand, does not show up as significant in this model. Model $1 \mathrm{~b}$ estimates the same regression with legal trust instead of de facto JI and the results are similar. Note that while we get similar diagnostic 
statistics, insample instability tests can now be computed as there are no dummy variables in the regression. They indicate slight instability of the variance estimator.

Table 1: Explaining the turnover rate

\begin{tabular}{|c|c|c|c|c|}
\hline Equation & (1a) & (1b) & $(2 a)$ & $(2 b)$ \\
\hline \multirow[t]{2}{*}{ Constant } & $0.418^{*}$ & $0.582 * *$ & 0.410 & 0.603 \\
\hline & $(0.184)$ & $(0.185)$ & $(0.342)$ & $(0.369)$ \\
\hline \multirow[t]{2}{*}{ de facto $\mathrm{JI}$} & $-0.485^{*}$ & & -0.341 & \\
\hline & $(0.216)$ & & $(0.215)$ & \\
\hline \multirow[t]{2}{*}{ Legal Trust } & & $-0.271(*)$ & & $-0.348^{*}$ \\
\hline & & $(0.140)$ & & $(0.128)$ \\
\hline \multirow[t]{2}{*}{ CEO } & 0.379 & -0.393 & 0.810 & 0.308 \\
\hline & $(0.300)$ & $(0.339)$ & $(0.707)$ & $(0.778)$ \\
\hline \multirow[t]{2}{*}{ LnChecks } & & & -0.048 & -0.023 \\
\hline & & & $(0.288)$ & $(0.281)$ \\
\hline \multirow[t]{2}{*}{ (LnChecks * CEO) } & & & -0.471 & -0.652 \\
\hline & & & $(0.606)$ & $(0.618)$ \\
\hline No. of observations & 46 & 34 & 46 & 34 \\
\hline $\mathrm{SE}$ & 0.320 & 0.318 & 0.303 & 0.285 \\
\hline $\mathrm{R}^{2}$ & 0.22 & 0.12 & 0.33 & 0.34 \\
\hline F-test & $\mathrm{F}(4,41)=2.82^{*}$ & $\mathrm{~F}(2,31)=2.02$ & $\mathrm{~F}(6,39)=3.16^{*}$ & $\mathrm{~F}(4,29)=3.65^{*}$ \\
\hline Normality test & $\mathrm{Chi}^{2}(2)=5.71$ & $\operatorname{Chi}^{2}(2)=4.81$ & $\mathrm{Chi}^{2}(2)=4.05$ & $\mathrm{Chi}^{2}(2)=3.79$ \\
\hline Heteroscedast. test & $F(6,34)=1.73$ & $\mathrm{~F}(4,26)=1.19$ & $F(10,28)=1.66$ & $\mathrm{~F}(8,20)=0.40$ \\
\hline $\begin{array}{l}\text { Heteroscedast. test } \\
\text { with cross-products }\end{array}$ & $\mathrm{F}(7,33)=1.54$ & $\mathrm{~F}(5,25)=0.91$ & N.A. & $\mathrm{F}(13,15)=0.39$ \\
\hline RESET & $\mathrm{F}(1,40)=0.01$ & $\mathrm{~F}(1,30)=0.01$ & $\mathrm{~F}(1,38)=1.03$ & $\mathrm{~F}(1,28)=5.54^{*}$ \\
\hline Instability variance & N.A. & $0.523^{*}$ & N.A. & 0.093 \\
\hline Instability joint & N.A. & 0.939 & N.A. & 1.259 \\
\hline
\end{tabular}

Notes: The symbols $(*),{ }^{*}, * *$ indicate significance at a $10 \%, 5 \%$, and $1 \%$ significance level.

Models 1a and 2a contain dummy variables for Brazil and Uganda to reduce the extent of nonnormality. Tests for heteroscedasticity are based on White (1980) using squares of regressors and squares of regressors plus cross-products, respectively. The normality test is due to Jarque 
and Bera (1987) with a small-sample correction, and the RESET test for misspecification is based on Ramsey (1969). The instability test is a within-sample test suggested by Hansen (1992).

In Model 2a, we add the veto power indicator put forward by Keefer and Stasavage (2003). Now the marginal significance level for de facto $\mathrm{JI}$ is 0.12 . It should be noted that while none of the other variables is significant, this is partially due to the collinearity between CEO and LnChecks. If one were to remove LnChecks, the remaining variables would be significant at a $5 \%$ level of significance, except for de facto, which gets a p-value of 0.11 . While the indicator is only marginally significant when using de facto JI, it becomes significantly negative at a 5\% level when including the legal trust variable as shown by the estimates of Model $2 \mathrm{~b}$. The RESET test indicates some misspecification, however. To allow for a relationship between checks and de facto JI, we also augment the above regression by interacting these two variables. It turns out, however, that the interaction is not significant (results omitted). Hence, we find that de facto JI has an additional influence on the turnover rate over and above the effect of institutional veto power and we interpret this as evidence for the indirect channel outlined above. The coefficient of determination of these regressions is not particularly high, and thus does not explain the turnover rate very well. This may be due to the fact that the turnover rate is a very noisy indicator of de facto CBI.

Table 2 summarizes the result related to the analysis of the direct influence of the legal system on the inflation rate. ${ }^{3}$ Model 3a regresses the de facto JI, degree of openness, and de jure CBI on the logarithm of the inflation rate. First, the diagnostic tests of Model 3a are fine except for some indication of misspecification. We find that openness has a significantly negative effect on inflation as shown earlier by Romer (1993).

3 We also estimated the effect of interacting legal trust and CBI. This variable is highly collinear to legal trust and slightly less significant. 
Table 2: Explaining the inflation rate in logs

\begin{tabular}{|c|c|c|c|c|}
\hline Equation & $(3 a)$ & $(3 b)$ & $(4 a)$ & $(4 b)$ \\
\hline Constant & $\begin{array}{l}-0.366 \\
(0.561)\end{array}$ & $\begin{array}{l}-0.543 \\
(0.514)\end{array}$ & $\begin{array}{l}-2.458 * * \\
(0.867)\end{array}$ & $\begin{array}{l}-2.264(*) \\
(1.156)\end{array}$ \\
\hline de facto $\mathrm{JI}$ & $\begin{array}{l}-1.787 * * \\
(0.592)\end{array}$ & & $\begin{array}{l}-0.789 \\
(0.702)\end{array}$ & \\
\hline Legal trust & & $\begin{array}{l}-0.904 * \\
(0.399)\end{array}$ & & $\begin{array}{l}-1.006^{* *} \\
(0.363)\end{array}$ \\
\hline de jure $\mathrm{CBI}$ & $\begin{array}{l}0.244 \\
(1.145)\end{array}$ & $\begin{array}{l}-0.583 \\
(1.275)\end{array}$ & $\begin{array}{l}5.888^{*} \\
(2.219)\end{array}$ & $\begin{array}{l}6.111\left(^{*}\right) \\
(3.328)\end{array}$ \\
\hline OPEN & $\begin{array}{l}-1.873 * * \\
(0.541)\end{array}$ & $\begin{array}{l}-4.217 * * \\
(1.227)\end{array}$ & $\begin{array}{l}-1.575 \\
(0.514)\end{array}$ & $\begin{array}{l}-2.583^{*} \\
(1.128)\end{array}$ \\
\hline POLCON & & & $\begin{array}{l}2.107(*) \\
(1.179)\end{array}$ & $\begin{array}{l}1.395 \\
(1.543)\end{array}$ \\
\hline $\begin{array}{l}(\mathrm{POLCON} * d e \\
\text { jure } \mathrm{CBI})\end{array}$ & & & $\begin{array}{l}-9.158 * * \\
(3.261)\end{array}$ & $\begin{array}{l}-9.000(*) \\
(4.437)\end{array}$ \\
\hline No. of observations & 51 & 34 & 51 & 34 \\
\hline SE & 1.023 & 0.949 & 0.939 & 0.797 \\
\hline $\mathrm{R}^{2}$ & 0.30 & 0.40 & 0.44 & 0.61 \\
\hline F-test & $\mathrm{F}(3,47)=6.83 * *$ & $\mathrm{~F}(3,30)=6.77 * *$ & $\mathrm{~F}(5,45)=7.02 * *$ & $\mathrm{~F}(5,28)=8.69 * *$ \\
\hline Normality test & $\mathrm{Chi}^{2}(2)=5.00$ & $\operatorname{Chi}^{2}(2)=0.04$ & $\operatorname{Chi}^{2}(2)=2.07$ & $\operatorname{Chi}^{2}(2)=3.69$ \\
\hline White test & $\mathrm{F}(6,40)=0.22$ & $\mathrm{~F}(6,23)=2.98^{*}$ & $F(10,34)=0.43$ & $F(10,17)=1.16$ \\
\hline $\begin{array}{l}\text { White test with } \\
\text { cross-products }\end{array}$ & $\mathrm{F}(9,37)=0.42$ & $\mathrm{~F}(9,20)=1.74$ & $\mathrm{~F}(19,25)=1.53$ & N.A. \\
\hline RESET & $\mathrm{F}(1,46)=7.32 * *$ & $\mathrm{~F}(1,29)=2.97\left(^{*}\right)$ & $\mathrm{F}(1,44)=0.36$ & $\mathrm{~F}(1,27)=0.70$ \\
\hline Instability variance & 0.068 & 0.060 & 0.288 & 0.083 \\
\hline Instability joint & 0.534 & 0.472 & 1.115 & 1.019 \\
\hline
\end{tabular}

Notes: See notes to Table 1.

De jure CBI, on the other hand, is not significantly different from zero. This is the well-known result that the relationship between formal $\mathrm{CBI}$ and inflation breaks down in a sample that 
includes countries that are not members of the OECD. ${ }^{4}$ However, our indicator of de facto JI is significant at the $1 \%$ level. A similar outcome is found when using legal trust instead of de facto $\mathrm{JI}$ as shown in Model 3b.

In Model 4a, we add a variable measuring the political constraints of a government (Polcon) and its interaction with de jure CBI. In Keefer and Stasavage (2003), this variable performed better with respect to explaining inflation than the LnChecks variable used in the turnover rate regression. It can be shown that this is also true for our sample (results omitted). Now we find that de jure CBI is significantly positive at a 5\% level, thus contradicting the basic hypothesis of higher CBI leading to lower inflation. However, the interaction between political constraints and de jure $\mathrm{CBI}$ is significantly negative. Only when the checks and balances are sufficiently strong does CBI have a negative impact on the inflation rate, which supports Keefer and Stasavage's argument. For instance, if both CBI and LnChecks take on their mean values, the net effect of CBI on inflation will be positive. POLCON on its own is significantly positive at the $10 \%$ level, which is not in accordance with their hypothesis. De facto JI is no longer significant, raising some doubts about the direct influence of the legal system on inflation. However, when we use the alternative indicator, legal trust, in Model $4 \mathrm{~b}$, we get a different outcome. Now there is a highly significant negative association between the degree of legal trust in a society and the inflation rate. The political constraint variables and de jure $\mathrm{CBI}$ on the other hand are less significant. Removing POLCON from the regression leads to Model 4c:

(4c) LnInflation $=-1.31-2.52 *$ Open $+3.44 *$ CBI $-5.19 * *$ (Polcon*CBI) $-1.12 * *$ Legal Trust

$$
(0.477)(1.12)
$$

4 See Sturm and de Haan (2001) for a discussion of this issue using an extended and edited data base. 
Observations: $34, \mathrm{SE}=0.794, \mathrm{R}^{2}=0.60, \mathrm{~F}(4,29)=10.7^{* *}$, Normality test: $\mathrm{Chi}^{2}(2)=3.98$, White test: $F(8,20)=1.06$, White test with cross-products: $F(14,14)=1.20$,

RESET: $F(1,28)=0.96$, Instability variance: 0.11 , Instability joint: 0.88 .

All the diagnostic tests are fine and all the variables are significant at the 5\% level. Moreover, the interaction between political constraints and CBI as well as our indicator for legal trust are even significant at a $1 \%$ level. The fit of the equation is quite good. The variables in Model 4c explain $60 \%$ of the variation in the logarithm of the inflation rate, while CBI and openness together can only explain $26 \%$. To summarize, inflation is lower when countries have a high degree of openness, de jure CBI and a relatively large number of political constraints, and legal trust. Thus, we found strong evidence for a direct channel from the legal system to inflation when considering legal trust.

Next we include the turnover rate into model $4 \mathrm{c}$ to see whether both, direct and indirect channel are present. This is a conservative test of the direct channel, as TOR might be endogenous with respect to the inflation rate and therefore upward biased. A consistent testing-down process leads to model 5.

(5) LnInflation $=-2.52+3.43 * \mathrm{CBI}-4.94 * *($ Polcon*CBI $)-0.89 *$ Legal Trust $+1.45 * *$ TOR

Observations: $34, \mathrm{SE}=0.740, \mathrm{R}^{2}=0.65, \mathrm{~F}(4,29)=13.5^{* *}$, Normality test: $\mathrm{Chi}^{2}(2)=3.13$, White test: $F(8,20)=1.16$, White test with cross-products: $F(14,14)=1.43$, RESET: $F(1,28)=0.28$, Instability variance: 0.19 , Instability joint: 0.64 .

Model 5 shows that significance of all variables in model $4 \mathrm{c}$ remains except for openness. Thus, there is evidence for a separate direct channel of the legal system on inflation. At the same time, 
legal trust is now only significant at the $5 \%$ level. Thus, some explanatory power of legal trust is taken up by the turnover rate, which reflects the impact of the indirect channel. Note that the interaction between POLCON and de jure CBI is even more significant. This suggests that there must be an additional direct channel present that links this interaction variable with the inflation rate that is not explored in Keefer and Stasavage (2003). We conclude, therefore, that there is evidence for both a direct influence as well as an indirect influence from the legal system to the inflation rate.

\section{Conclusion}

This paper analyses the relationship between de facto central bank independence, inflation, and the legal system. We argue that a more independent legal system is an important determinant of both de facto $\mathrm{CBI}$ and inflation. The independence of the legal system is measured via two indicators, de facto judicial independence and legal trust. The former is an indicator based on Feld and Voigt (2003), the latter is computed from the World Values Survey. The influence of the legal system on the inflation rate works via two channels, an indirect and a direct one. The indirect channel is based on the strengthening of de facto $\mathrm{CBI}$ in the case of an independent and trustworthy legal system. The direct channel suggests that higher judicial independence lowers transaction costs within the economy and thereby increases efficiency. Consequently, we would expect a fall in the natural rate of unemployment and an increase in potential output. Within simple but widely used models of monetary policy, we show that this will lead to a reduction of the equilibrium rate of inflation (Barro and Gordon 1983) and a fall of the average rate of inflation over the relevant time period (Svensson 1997).

Putting our hypothesis to the test, we find that there is both evidence of an indirect channel of the legal system affecting inflation via de facto $\mathrm{CBI}$ as well as for a direct channel. Evidence for the working of the indirect channel is demonstrated within a regression explaining de facto CBI 
as proxied by the central bank governor turnover rate. A higher degree of de facto JI or legal trust will decrease the turnover rate, controlling for the influence of the formal length of office and the checks and balances working within the executive and legislative branches of government. The direct relationship between the legal system and inflation is investigated in a regression explaining the logarithm of the inflation rate. Controlling for the influence of openness, de jure CBI, political constraints, and political constraints interacted with de jure CBI, we show that legal trust in particular adds a substantial degree of explanatory power. In our sample, such a model can explain $60 \%$ of the variation in the logarithm of the inflation rate. We also establish that the direct influence of the legal system on the inflation rate is present even if we control for the working of the indirect channel. Thus, both channels appear to affect the change in prices as separate channels, although we find more robust evidence for the direct effect. Hence, in addition to traditional factors, such as central bank independence or openness, or alternative factors (surveyed in Hayo and Hefeker 2002), such as interest group influences or public inflation aversion, the legal system appears to be yet another noteworthy determinant of the average inflation rate. 


\section{Appendix}

\section{Sample}

The countries considered in the empirical analysis are:

Table 1:

Legal Trust (34 countries): Argentina, Australia, Austria, Belgium, Brazil, Chile, China, Colombia, Denmark, Finland, France, Germany, Ghana, Hungary, Iceland, India, Italy, Japan, Korea (South), Mexico, Netherlands, Nigeria, Pakistan, Peru, Philippines, South Africa, Spain, Sweden, Switzerland, Turkey, UK, USA, Uruguay, Venezuela.

De facto JI (46 countries): In addition to those of Legal Trust: Botswana, Costa Rica, Egypt, Greece, Israel, Kenya, Malaysia, Nepal, New Zealand, Norway, Panama, Uganda.

Table 2:

Legal Trust (34 countries): see above

De facto JI (51 countries): ): In addition to those of Legal Trust: Bolivia, Botswana, Costa Rica, Egypt, Greece, Israel, Kenya, Malaysia, Nepal, New Zealand, Nicaragua, Norway, Panama, Singapore, Uganda, Zambia, Zimbabwe. 


\section{De facto JI}

The indicator for de facto JI is based on the following list of eight variables (see Feld and Voigt 2003). All variables can take on values between 0 and 1 . The unweighted sum of the variables is then divided by the number of variables for which information is available.

(1-3) A crucial aspect of de facto JI will be the effective average term length of the members of the highest court.5 If the actual term length and the one to be expected on the basis of the legal foundations deviate, this is interpreted as a signal for a low level of factual independence. Removing a judge before the end of term is a serious breach of $\mathrm{JI}$ and countries where this has occurred get a low score.

(4) The influence of a judge depends on the number of other judges who are members of the same court. By increasing the number of judges, the weight of the sitting judges can be reduced. The de facto indicator counts how many times the number of judges has been changed since 1960.

(5-6) In order to be factually independent, judges need to be paid adequately. It was therefore inquired whether the incomes of judges have at least remained constant in real terms since 1960. But the efficacy of courts does not only depend on the income level of their judges but also on the number of clerks employed, the size of the library, the availability of modern computer equipment etc. This aspect has been taken into account by asking for the development of the court's budget as an organization (also since 1960).

5. This variable is closely reminiscent of the turnover rate calculated for central bank governors and used as a proxy for their de facto independence. Henisz (2000) has calculated this variable for the tenure of supreme court judges for 45 countries for the period from 1960 to 1990. 
(7) Any change in the basis of the legal foundation of the highest court will increase uncertainty among its potential users, i.e. will be counter to one of the most fundamental functions of the law. Frequent changes of the respective legal rules are therefore interpreted as an indicator for low de facto independence.

(8) The de facto degree of judicial independence is low if decisions of the highest court, in order to be implemented, depend on some action of one (or both) of the other branches of government and this cooperation is not granted. The more frequently this has been the case, the less independent is JI supposed to be factually. 


\section{References}

Barro, R. J. and D. Gordon (1983); Rules, Discretion, and Reputation in a Positive Model of Monetary Policy, Journal of Monetary Economics 12: 101-121.

Berger, H., J. de Haan and S. Eijffinger (2001); Central Bank Independence: An Update of Theory and Evidence, Journal of Economic Surveys 15: 3-40.

Cukierman, A. (1992); Central Bank Strategy, Credibility, and Independence, Cambridge: MIT Press.

Cukierman, A. and S. Webb (1995); Political Influence on the Central Bank: International Evidence, World Bank Economic Review 9:3.

Cukierman, A., S. Webb und B. Neyapti (1992); Measuring the Independence of Central Banks and its Effects on Policy Outcomes, The World Bank Economic Review 6: 353-98.

Debelle, G. und S. Fischer (1995); How Independent Should a Central Bank Be? In: J.C. Fuhrer (ed.); Goals, Guidelines and Constraints Facing Monetary Policymakers, Federal Reserve Bank of Boston, Conference Series No. 38, Boston, 195-221.

Feld, L. and S. Voigt (2003); Economic Growth and Judicial Independence: Cross Country Evidence Using a New Set of Indicators, European Journal of Political Economy, 19(3):497-527.

Feld, L. and S. Voigt (2004); "Making Judges Independent - Some Proposals Regarding the Judiciary”. CESifo Working Paper Series No. 1260. http://ssrn.com/abstract=597721

Forder, J. (1996); “On the measurement and assessment of 'institutional' remedies”. Oxford Economic Papers 48, 39-51.

Forder, J. (1998); “The case for an independent central bank: A reassessment of evidence and sources”. European Journal of Political Economy 14, 53-71.

Grilli, V., D. Masciandaro and G. Tabellini (1991); Political and Monetary Institutions and Public Financial Policies in the Industrial Countries, Economic Policy 13: 341-92. 
Hansen, B.E. (1992); Testing for Parameter Instability in Linear Models, Journal of Policy Modeling 14: 517-533.

Hayo, B. (1998); Inflation culture, central bank independence and price stability, European Journal of Political Economy 14: 241-63.

Hayo, B. and C. Hefeker (2002); Do we really need central bank independence? A critical reexamination, European Journal of Political Economy 18: 653-674.

Hayo, B. and S. Voigt (2003); Explaining de facto judicial independence, Volkswirtschaftliche Diskussionsbeiträge 47/03, University of Kassel.

Henisz, W. (2000); The Institutional Environment for Economic Growth, Economics and Politics 12(1): 1-31.

Jarque, C.M. and A.K. Bera (1987); A test for normality of observations and regression residuals, International Statistical Review 55, 163-172.

Keefer, P. (2002); Politics and the Determinants of Banking Crises: The Effects of Political Checks and Balances. In: L. Hernandez and K. Schmidt-Hebbel (eds.): Banking, Financial Integration, and International Crises, Santiago: Central Bank of Chile, 85-112.

Keefer, P. and D. Stasavage (2003); The Limits of Delegation: Veto Players, Central Bank Independence and the Credibility of Monetary Policy, American Political Science Review 97: 407-423.

Kydland, F. and E. Prescott (1977); Rules Rather than Discretion: The Inconsistency of the Optimal Plans, Journal of Political Economy 85: 473-91.

Moser, P. (1999); Checks and Balances and the supply of central bank independence, European Economic Review 43: 1569-93.

Posen, A. (1993); Why central bank independence does not cause low inflation: There is no institutional fix for politics, in: R. O’Brien (ed.), Finance and the International Economy 7, Oxford: OUP. 
Ramsey, J.B. (1969); Tests for specification errors in classical linear least squares regression analysis, Journal of the Royal Statistical Society B 31, 350-371.

Rogoff, K. (1985); The Optimal Degree of Commitment to an Intermediate Monetary Target, Quarterly Journal of Economics 100: 1169-1190.

Romer, D. (1993); Openness and Inflation: Theory and Evidence, Quarterly Journal of Economics 108(4):869-903.

Sturm, J.E. and J. de Haan (2001); Inflation in developing countries: does central bank independence matter? New evidence based on a new dataset, mimeo, University of Groningen, the Netherlands.

Svensson, L. (1997); Inflation forecast targeting: Implementing and monitoring inflation targets, European Economic Review 41, 1111-1146.

White, H. (1980); A heteroskedastic-consistent covariance matrix estimator and a direct test for heteroskedasticity, Econometrica 48, 817-838.

World Values Study Group (2000); World Values Survey 1981-1984, 1990-1993, and 19951997. Interuniversity Consortium for Political and Social Research, Ann Arbor. 